\title{
Perbandingan Efektivitas Penggunaan Vibration Anesthesia Device (VAD) dengan Krim Campuran Eutektik (EMLA) dalam Mengurangi Nyeri Pemasangan Peripheral Intravenous Catheter (PIVC)
}

\author{
Anas Alatas ${ }^{1 *}$, Irfan Meison Hardi ${ }^{1}$, Eddy Harijanto ${ }^{1}$
}

1. Departemen Anestesiologi dan Terapi Intensif, Fakultas Kedokteran Universitas Indonesia, RSUPN Dr. Cipto Mangunkusumo, Jakarta, Indonesia

\begin{abstract}
ABSTRAK
Latar Belakang: Pemasangan Peripheral Intravenous Catheter (PIVC) merupakan salah satu prosedur invasif terbanyak yang dilakukan di rumah sakit dan sering menyebabkan rasa nyeri pada pasien. Berbagai cara diterapkan dalam mengurangi rasa nyeri yang ditimbulkan saat pemasangan PIVC, antara lain dengan penggunaan Vibration Anesthesia Device (VAD) dan krim campuran eutektik (EMLA). Penelitian ini bertujuan untuk mengetahui efektivitas VAD dibandingkan dengan pemberian EMLA untuk mengurangi nyeri pada saat pemasangan PIVC.

Metode: Penelitian ini adalah uji eksperimental tidak tersamar pada pasien yang akan direncanakan menjalani pembedahan mata di kamar operasi Kirana RSUPN dr. Cipto Mangunkusumo selama bulan September - Oktober 2018. Sebanyak 56 subjek diambil dengan metode consecutive sampling dan dibagi ke dalam 2 kelompok. Pasien secara acak dilakukan pemasangan PIVC dengan bantuan VAD atau dengan EMLA. Keefektifan akan dinilai dari skala nyeri visual analog scale (VAS) dan perbedaan frekuensi nadi sebelum dan sesudah dilakukan tindakan. Analisis data dilakukan dengan uji T dan Mann Whitney.

Hasil: Tidak terdapat perbedaan bermakna dalam skala VAS yang dilaporkan oleh subjek dari kelompok VAD 13.65 (10.25 -18.17) dan EMLA 12.57 (8.97 - 17.61) dengan nilai $p=0.706$. Perubahan frekuensi nadi antara kedua kelompok tidak menunjukkan adanya perbedaan signifikan $(p=0,557)$. Didapatkan peningkatan frekuensi nadi yang lebih tinggi pada kelompok VAD 2 (-3-19) dibandingkan kelompok EMLA $2(-3-16)$.

Simpulan: VAD sama efektif dibandingkan dengan EMLA dalam mengurangi nyeri pada pemasangan PIVC.
\end{abstract}

Kata Kunci: EMLA, nyeri, PIVC, VAD, VAS 


\title{
Comparison of Effectiveness of Vibration Anesthesia Device (VAD) with Eutectic Cream Mixture for Reducing Pain in Peripheral Intravenous Catheter (PIVC) Insertion
}

\author{
Anas Alatas ${ }^{1 *}$, Irfan Meison Hardi ${ }^{1}$, Eddy Harijanto ${ }^{1}$
}

1. Departement of Anesthesiology and Intensif Care, Faculty of Medicine, Universitas Indonesia, Dr. Cipto Mangunkusumo National General Hospital, Jakarta, Indonesia

\begin{abstract}
Background: Peripheral Intravenous Catheter (PIVC) is one of the most invasive procedures performed in hospitals and often causes pain in patients. Various methods have been applied to reduce the pain caused by PIVC insertion, including the use of a Vibration Anesthesia Device (VAD) and a mixed eutectic cream (EMLA). This study aimed to determine the effectiveness of VAD compared to EMLA administration to reduce pain during PIVC insertion.

Methods: This is an experimental study that is not disguised in patients who are planned to undergo eye surgery in the Kirana operating theathre, Dr. Cipto Mangunkusumo hospital during SeptemberOctober 2018. A total of 56 subjects were taken by consecutive sampling method and divided into 2 groups. Patients were randomly assigned to PIVC insertion with Vibration Anesthesia Device (VAD) or with eutectic mixed cream (EMLA). Effectiveness will be assessed from pain visual analog scale (VAS) and heart rate frequency differences before and after insertion. Data analysis was performed by T-Test and Mann Whitney test.
\end{abstract}

Results: There were no significant differences in the VAS scale reported by subjects from the VAD group 13.65 (10.25 -18.17) $\mathrm{mm}$ and EMLA group 12.57 (8.97 - 17.61) $\mathrm{mm}$ with $p=0.706$. Changes in pulse frequency between the two groups also showed no significant differences $(p=0.557)$. However, there was a higher increase in pulse frequency in the VAD 2 group (-3 - 19) compared to the EMLA 2 group (-3 - 16).

Conclusion: VAD is equally effective compared to EMLA in reducing pain in Peripheral Intravenous Catheter (PIVC) insertion.

Keywords: EMLA, Pain, PIVC, VAD, VAS 


\section{PENDAHULUAN}

Pemasangan Peripheral Intravenous Catheter (PIVC) merupakan salah satu prosedurinvasifyang paling banyak dilakukan di rumah sakit dengan lebih dari $70 \%$ pasien rawat inap membutuhkan pemasangan infus selama masa perawatan. ${ }^{1}$ Sebanyak $40 \%$ pasien dilakukan pemasangan PIVC sebagai akses pengambilan sampel darah, dan sebanyak $25 \%$ pasien dipasangan PIVC sebagai akses untuk terapi cairan di unit gawat darurat (UGD). Pemasangan PIVC pada pasien penting untuk berbagai intervensi terapeutik, seperti terapi cairan, penggantian elektrolit, terapi antibiotik, nutrisi parenteral, pemberian zat kontras, dan prosedur anestesia. ${ }^{2}$

Pada pasien yang telah dipasang PIVC, angka kekerapan pemasangan ulang PIVC relatif tinggi berkisar antara 33\% - 69\%. Hal tersebut dapat disebabkan karena kanul yang tercabut, rasa nyeri, phlebitis, oklusi dan infeksi. ${ }^{1}$ Pemasangan ulang PIVC ini akan menyebabkan stres, meningkatnya persepsi nyeri, dan menurunkan tingkat kepuasan pasien dan tenaga kesehatan. ${ }^{3}$ Penggantian PIVC dianjurkan setiap 70 jam - 96 jam untuk mencegah terjadinya infeksi. ${ }^{4}$

Prosedur PIVC yang menggunakan jarum akan menyebabkan kecemasan, rasa takut, dan trauma pada pasien anak maupun dewasa. ${ }^{5}$ Kecemasan akan menyebabkan peningkatan respons simpatik seperti berkeringat, perasaan lelah dan gugup, takikardi, dan hipertensi. Peningkatan respons simpatik tersebut dapat menyebabkan beberapa kerugian diantaranya meningkatkan konsumsi oksigen dan meningkatkan kebutuhan akan dosis obat anestesi selama prosedur tindakan. ${ }^{6}$

Metode untuk mengurangi rasa nyeri pada saat prosedur pemasangan PIVC, terdiri dari metode non-farmakologis (psikologis) dan dan metode farmakologis. 5,7 Metode yang digunakan untuk mengurangi rasa nyeri selama prosedur pemasangan PIVC harus efektif, bebas nyeri, cepat, efek samping minimal dan murah. Metode non-farmakologis yang seringkali dipakai adalah dengan merangsang batuk dan maneuver valsava. Metode farmakologis yang seringkali dipakai diantaranya injeksi anestesi lokal, anestesi topikal dengan EMLA, koyo obat anti inflammasi non-steroid, iontophoresis, vapocoolant agent dan ultrasound. ${ }^{5,8}$
Krim campuran lidokain dan prilokain dengan campuran 1:1 (2.5\%: 2.5\%), akan menghasilkan efek eutektik. Campuran euktektik ini merupakan campuran yang memiliki titik leleh yang lebih rendah dibandingkan dengan titik leleh masingmasing obat bila tidak dicampurkan. EMLA telah digunakan secara klinis sejak 25 tahun yang lalu. Banyak penelitian klinis yang menyatakan bahwa EMLA memiliki efek analgesia pada prosedur pungsi vena dan pemasangan PIVC baik pada pasien anak maupun dewasa. ${ }^{9}$ Penelitian yang dilakukan oleh Celik dkk. membandingkan pemberian vapocoolant spray, krim EMLA, dan krim placebo pada pasien hemodialisis yang akan dilakukan kanulasi vena. Hasil penelitian menunjukkan kelompok pasien yang mendapatkan vapocoolant spray ditemukan nyeri dengan nilai VAS $14 \pm 12.4 \mathrm{~mm}$. Kelompok pasien yang mendapatkan EMLA ditemukan nyeri dengan nilai VAS $10.7 \pm 10.6 \mathrm{~mm}$. Kelompok pasien yang mendapatkan placebo ditemukan nyeri dengan nilai VAS $33.4 \pm 19.5 \mathrm{~mm} .{ }^{10}$

Salah satu metode terbaru yang bisa digunakan untuk mengurangi nyeri pemasangan PIVCadalah Vibration Anesthesia Device (VAD). ${ }^{9,11}$ Metode ini dapat menghilangkan nyeri saat penyuntikan obat (botox) dan tidak ditemukan adanya efek samping. ${ }^{11}$ VAD dikembangkan berdasarkan teori gate-control of pain dari Wall dan Melzack (1965). VAD bekerja dengan cara menimbulkan sensasi getar pada kulit yang akan menurunkan atau menghilangkan transmisi nyeri ke otak. Otak akan melakukan persepsi sensasi getar terlebih dahulu sebelum sensasi nyeri muncul, sehingga otak tidak dapat melakukan persepsi terhadap sensasi nyeri. ${ }^{12}$ Mally dkk. melakukan penelitian dengan hasil bahwa getaran adalah metode yang aman dan efektif untuk mencapai anestesi selama penyuntikan dermal filler di wajah. ${ }^{13}$

Saat ini belum ada penelitian yang menilai efektivitas VAD untuk mengurangi nyeri pada saat pemasangan PIVC di Indonesia. Penelitian ini bertujuan untuk mengetahui efektivitas VAD dibandingkan dengan pemberian EMLA untuk mengurangi nyeri pada saat pemasangan PIVC. Bila VAD sama atau lebih efektif dibandingkan dengan krim EMLA dalam mengurangi nyeri pada pemasangan PIVC, VAD dapat menjadi alternatif dalam mengurangi nyeri pada pemasangan PIVC. 


\section{METODE PENELITIAN}

\section{Desain Penelitian}

Penelitian ini adalah uji eksperimental tidak tersamar. Subjek penelitian dipilih secara konsekutif pada pasien yang akan direncanakan menjalani pembedahan mata di kamar operasi Instanti Kirana Rumah Sakit Umum Pusat Nasional Cipto Mangunkusumo (RSCM). Perkiraan jumlah sampel pada penelitian ini menggunakan rumus besar subjek penelitian analitik komparatif numerik tidak berpasangan dua kelompok satu kali pengukuran dengan perkiraan drop out sebesar 20\%, maka jumlah sampel yang dibutuhkan sebesar 56 orang. Pengambilan sampel dilakukan setelah mendapat persetujuan dari Komite Etik Fakultas Kedokteran Universitas Indonesia dengan No. Etik 0821/UN2.F1/ETIK/2018.

\section{Kriteria Inklusi dan Ekslusi}

Pasien yang dijadwalkan untuk menjalani pembedahan mata akan dievaluasi kelayakannya untuk diikutsetakan dalam penelitian ini. Kriteria penerimaan pada pasien ini adalah pasien dengan usia 18 - 65 tahun, status fisik ASA I II, dijadwalkan untuk menjalani pembedahan elektif mata dan bersedia menjadi peserta penelitian dan mematuhi aturan penelitian. Kriteria penolakan pasien pada penelitian ini adalah pasien yang membutuhkan pemasangan PIVC ukuran besar (lebih dari $20 \mathrm{G}$ ), sudah pernah dipasang PIVC dalam 72 jam terakhir, memiliki riwayat gangguan neurologis (riwayat stroke, cedera kepala, gangguan mental dan inteligensi, diabetik neuropati), mendapatkan analgetik dalam 24 jam terakhir, riwayat gangguan irama jantung, riwayat kemoterapi / kesulitan pemasangan PIVC sebelumnya dan tingkat pendidikan kurang dari sekolah menengah pertama (SMP). Kriteria pengeluaran adalah pasien yang tidak berhasil dipasang PIVC pada percobaan pertama.

\section{Protokol Penelitian}

Pasien yang telah memenuhi kriteria inklusi dilakukan informed consent dan dipersiapkan untuk menjalani prosedur pemasangan PIVC. Subjek penelitian akan dibagi menjadi dua kelompok yaitu pasien yang akan dilakukan pemasangan PIVC dengan bantuan Vibration Anesthesia Device (VAD) sebagai kelompok perlakuan dan pasien yang akan dilakukan pemasangan PIVC dengan krim campuran eutektik (EMLA). Keefektifan akan dinilai dari skala nyeri Visual Analog Scale (VAS) nyeri dan perbedaan frekuensi nadi sebelum dan sesudah tindakan.

Randomisasi dilakukan dengan menggunakan amplop tertutup yang berisi kode yang hanya akan diketahui oleh peneliti (concealment). Pasien akan diberitahu mendapat zat krim EMLA atau VAD. Saat sampai di ruang penerimaan pasien, pasien tidak diberikan premedikasi. Kemudian dilakukan pengukuran dan pencatatan frekuensi nadi sebelum tindakan.

Setelah dilakukan identifikasi lokasi yang akan dilakukan pemasangan PIVC (bagian dorsal tangan kanan atau kiri), dilakukan pemasangan karet tourniquet di bagian proksimal daerah yang akan dilakukan pemasangan PIVC. Pada kelompok EMLA, krim aklan dioleskan 45-60 menit sebelum tindakan dilakukan dan ditutupi dengan transparent draping. Draping akan di cabut sebelum penyuntikan, kemudian krim dihilangkan. Pada kelompok Vibration Anesthesia Device, alat akan di tempelkan dengan bantuan asisten di sekitar daerah yang akan dilakukan pemasangan PIVC setelah dibersihkan dengan kapas alkohol.

Operator akan minta izin saat akan melakukan mulai melakukan pemasangan PIVC. Dilakukan pemasangan PIVC dengan Vasofix ${ }^{\circledR} 20$ G. Pemasangan kanul dilakukan di bagian dorsal tangan kanan atau kiri oleh residen anestesiologi tahap mandiri. dan kemudian frekuensi nadi akan dinilai kembali saat semua PIVC sudah berada di dalam pembuluh darah. Setelah selesai pemasangan, pasien ditanyakan tentang derajat nyeri menggunakan skala VAS nyeri dan kemudian pencatatan dilakukan oleh peneliti.

\section{Analisis Statistik}

Data yang telah diperoleh kemudian dianalisis dengan menggunakan program komputer Statistical Package for Social Sciences (SPSS) versi 21.0. Data kategorik disajikan dalam bentuk jumlah dan presentase (n (\%)). Data numerik disajikan dalam bentuk rerata \pm simpang baku bila sebaran data normal atau dalam bentuk 
median (nilai minimum-maksimum) bila sebaran tidak normal. Uji T tidak berpasangan dan uji Mann-Whitney digunakan untuk menganalisis dua variabel numerik. Hasil analisis dianggap bermakna bila nilai $p<0,05$.

\section{HASIL PENELITIAN}

Penelitian ini melibatkan 56 sampel yang terdiri atas 28 pasien yang diberi EMLA dan 28 pasien yang diberi VAD. Sebanyak 2 pasien dari kelompok VAD mengalami drop out karena percobaan pemasangan PIVC lebih dari satu kali (double puncture). Dengan demikian, jumlah sampel pada kelompok VAD menjadi 26 subjek (Tabel 1).

Perbandingan VAS Nyeri Kelompok VAD dan EMLA

Sebanyak 56 sampel yang terlibat dalam penelitian diberikan intervensi pemberian
EMLA atau VAD dan dilakukan pemasangan PIVC. Salah satu parameter yang dinilai adalah nyeri berdasarkan skala VAS. Setelah dikonversi, uji normalitas menunjukkan data nilai VAS berdistribusinormal. Hasil uji T-test menunjukkan tidak terdapat perbedaan bermakna pada VAS nyeri antara kelompok yang mendapatkan VAD dengan EMLA (Tabel 2).

Perbandingan Perubahan Frekuensi Nadi Kelompok VAD dan EMLA

Parameter lain yang dinilai dalam pemasangan PIVC setelah pemberian intervensi dengan EMLA atau VAD adalah perubahan frekuensi nadi sebelum dan sesudah tindakan. Uji normalitas data menunjukkan perubahan frekuensi nadi memiliki distribusi tidak normal. Hasil uji MannWhitney menunjukkan tidak terdapat perbedaan bermakna perubahan frekuensi nadi antara kelompok VAD dengan EMLA (Tabel 3).

Tabel 1. Karakteristik subjek penelitian

\begin{tabular}{lcc}
\hline Variabel & VAD (n=26) & EMLA (n=28) \\
\hline Jenis kelamin & $12(41,4)^{\mathrm{a}}$ & $17(58,6)^{\mathrm{a}}$ \\
Perempuan & $14(56)^{\mathrm{a}}$ & $11(44)^{\mathrm{a}}$ \\
Laki-laki & $41,46(13,33)^{\mathrm{b}}$ & $39,32(12,61)^{\mathrm{b}}$ \\
Usia (tahun) & & \\
Tingkat pendidikan & $9(34,6)^{\mathrm{a}}$ & $10(35.7)^{\mathrm{a}}$ \\
SMP & $12(46,2)^{\mathrm{a}}$ & $7(25)^{\mathrm{a}}$ \\
SMA & $5(19.2)^{\mathrm{a}}$ & $11(39.3)^{\mathrm{a}}$ \\
S1 & $60,69(13,06)^{\mathrm{b}}$ & $63,75(14,53)^{\mathrm{b}}$ \\
Berat badan (kg) & $1,60(0,07)^{\mathrm{b}}$ & $1,61(0,09)^{\mathrm{b}}$ \\
Tinggi badan (m) & $23,47(3,82)^{\mathrm{b}}$ & $24,49(4,21)^{\mathrm{b}}$ \\
Indeks Massa Tubuh*(kg/m2) & & $12(60)^{\mathrm{a}}$ \\
Status fisik ASA & $8(40)^{\mathrm{a}}$ & $16(47,1)^{\mathrm{a}}$ \\
ASA 1 & $18(52,9)^{\mathrm{a}}$ & \\
ASA 2 & & \\
anilai dalam persentase \\
nilai dalam rata-rata (Standar Deviasi)
\end{tabular}

Tabel 2. Perbandingan VAS Nyeri Kelompok VAD dan EMLA

\begin{tabular}{llll}
\hline & VAD $(\mathbf{n}=\mathbf{2 6})$ & EMLA $(\mathbf{n}=\mathbf{2 8})$ & nilai $\mathbf{p}$ \\
VAS nyeri* & $13.65(10.25-18.17)$ & $12.57(8.97-17.61)$ & 0.706 \\
\hline "data disajikan dalam rerata geometrik (IK 95\%) & &
\end{tabular}


Tabel 3. Perbandingan VAS Nyeri Kelompok VAD dan EMLA

\begin{tabular}{llll}
\hline & VAD $(\mathbf{n}=\mathbf{2 6})$ & EMLA $(\mathbf{n}=\mathbf{2 8})$ & nilai $\mathbf{p}$ \\
Perubahan frekuensi nadi* & $2(-3-19)$ & $2(-3-16)$ & 0,557 \\
\hline data disajikan dalam median (minimum-maksimum) &
\end{tabular}

\section{PEMBAHASAN}

Dari 56 pasien yang telah memenuhi kriteria inklusi dan eksklusi untuk menjadi subjek penelitian pada penelitian ini, 2 pasien dari kelompok VAD harus mengalami drop out karena percobaan pemasangan PIVC lebih dari satu kali (double puncture). Hal ini dapat disebebkan karena pengambilan data pada kedua subjek tersebut dilakukan pada hari pertama pengambilan data, sehingga operator belum beradaptasi terhadap lampu biru dan getaran yang dihasilkan oleh VAD. Kemungkinan lainnya yaitu dari aspek subjek, dimana kedua subjek tersebut kemungkinan tergolong dalam kategori sulit untuk dilakukan kateterisasi. $\mathrm{Hal}$ ini dapat dicegah dengan menentukan kriteria eksklusi tambahan yaitu pasien dengan riwayat sulit untuk dilakukan pungsi vena atau yang dinilai akan sulit untuk dikanulasi, seperti yang dilakukan pada studi oleh Speirs dkk. ${ }^{10}$ Keputusan untuk melakukan drop out pada kedua subjek ini didukung studi oleh RodriguezCalero dkk yang menyatakan bahwa pungsi lebih dari satu kali dapat menyebabkan stres dan meningkatkan persepsi nyeri pasien sehingga dapat mempengaruhi hasil pengukuran skala VAS dan frekuensi nadi pada penelitian ini. ${ }^{3}$

Data karakteristik subjek penelitian mencakup jenis kelamin, usia, berat badan, tinggi badan, indeks massa tubuh, dan status fisik ASA. Persepsi dan respon terhadap nyeri bersifat subjektif dan dapat dipengaruhi oleh faktor seperti ras, jenis kelamin, usia dan tingkat pendidikan. ${ }^{14-16}$ Meski demikian, pada studi ini, tidak terdapat perbedaan bermakna pada jumlah subjek perempuan dan laki-laki serta rerata usia antara kelompok VAD dan EMLA. Rerata usia pasien pada kelompok VAD yaitu 41,46 +/- 13,33 tahun, sedangkan pada kelompok EMLA yaitu $39,32+/-$ 12,61 tahun $(p=0,548)$. Pada kedua kelompok, mayoritas subjek merupakan ras melayu dan berada dalam kelompok usia 41-50 tahun.

Demikian pula dari segi status antropometri (berat badan, tinggi badan, dan IMT) tidak ditemukan adanya perbedaan antara kelompok VAD dan EMLA. Data antropometri diambil untuk menghilangkan bias kesulitan pemasangan PIVC yang dipengaruhi oleh obesitas Status fisik ASA subjek pada kedua kelompok juga sebanding, meskipun pada kelompok VAD lebih banyak subjek (52,9\%) yang memiliki skor ASA 2, sedangkan pada kelompok EMLA lebih banyak subjek (60\%) yang memiliki skor ASA 1.

Berdasarkan paparan di atas, dapat disimpulkan bahwa karakteristik demografis serta klinis subjek telah tersebar merata antara kedua kelompok. Dengan demikian, variabel-variabel tersebut tidak mempengaruhi keluaran yang diteliti pada studi ini yaitu skala nyeri VAS dan frekuensi nadi subjek.

\section{Perbandingan Nyeri Kelompok EMLA dan VAD}

Hasil studi ini menunjukan tidak terdapat perbedaan bermakna dalam skala VAS yang dilaporkan oleh subjek dari kelompok VAD 13.65 (10.25 -18.17) mm dan EMLA 12.57 (8.97 17.61) $\mathrm{mm}$ dengan nilai $\mathrm{p}=0.706$.

Belum terdapat studi yang membandingkan secara langsung efikasi antara VAD dan EMLA dalam menurunkan nyeri pada pemasangan PIVC. Pada penelitian ini, secara statistik tidak terdapat perbedaan bermakna antara skala VAS pada kelompok VAD dan EMLA sehingga dapat dikatakan VAD sama efektif dibandingkan dengan EMLA dalam mengurangi nyeri yang dinilai dengan menggunakan VAS nyeri. Hal ini sesuai dengan hipotesis penelitian yang menyatakan VAD sama efektif dibandingkan dengan krim EMLA dalam mengurangi nyeri pada prosedur pemasangan Peripheral Intravenous Catheter (PIVC).

Ditinjau dari segi lain diluar penurunan skala VAS, VAD juga memiliki beberapa keunggulan lain jika dibandingkan dengan EMLA. Yang pertama yaitu dari segi awitan, dimana EMLA membutuhkan waktu 30-60 menit. ${ }^{17,18}$ sebelum awitan 
efek anestesinya, sedangkan pada VAD, efek anestesi dapat langsung terjadi karena getaran yang dihasilkan akan segera menstimulasi mekanoreseptor dan serat berdiameter besar, dan dengan demikian menghambat transmisi nyeri ke otak. ${ }^{19}$

Selain itu, dari segi praktikal dan ekonomi, EMLA membutuhkan barang medis habis pakai berupa draping transparan. Harga EMLA juga masih tergolong cukup mahal. Sedangkan penggunaan alat VAD tidak memerlukan barang medis habis pakai. Dari segi prosedural, operator juga mengeluhkan bahwa pada kelompok EMLA, pembuluh darah subjek mengalami vasokonstriksi sehingga menyulitkan proses pemasangan PIVC. Hal ini terkait salah satu efek samping yang memang ditimbulkan oleh EMLA yaitu vasokonstriksi pembuluh darah. ${ }^{20}$ $\mathrm{Hal}$ ini dapat terjadi karena $\mathrm{pH}$ dari krim EMLA yang tinggi $(\mathrm{pH}$ 9.2) menyebabkan perubahan keseimbangan ion di membran saraf lapisan kulit luar dan menyebabkan vasokonstriksi. ${ }^{21,22}$ Namun studi lain juga menyatakan bahwa perubahan diameter vena dan ketebalan kulit setelah pemberian krim EMLA tidak terlalu signifikan untuk kanulasi vena. ${ }^{23}$

Meski demikian, kesulitan yang dialami selama penggunaan VAD adalah adanya lampu biru yang menyulitkan visualisasi vena. Lampu berwarna biru ini digunakan untuk menandai area yang mendapatkan getaran yang paling baik. Getaran yang ditimbulkan oleh alat VAD juga menimbulkan rasa kurang nyaman bagi operator saat melakukan pemasangan PIVC. Oleh karena itu, diperlukan beberapa kali latihan agar operator dapat beradaptasi untuk memasang PIVC yang dibantu dengan VAD.

VAD yang bekerja dengan prinsip gate control theory of pain, sama efektif mengurangi nyeri dibandingkan dengan EMLA yang memiliki mekanisme kerja menghambat transmisi impuls saraf (blok konduksi). ${ }^{21,23}$

Melihat adanya berbagai keuntungan yang dapat diberikan oleh VAD dan kemampuannya menurunkan skala VAS yang sama efektifnya dengan EMLA pada penelitian ini, dapat dilakukan studi lebih lanjut untuk membandingkan efikasi VAD dengan EMLA dengan penggunaan skala nyeri yang berbeda.
Perbandingan Perubahan Frekuensi Nadi Kelompok EMLA dan VAD

Selain skala VAS, studi ini juga mempelajari perbedaan perubaan frekuensi nadi pada pasien yang dilakukan pemasangan PIVC dengan VAD dan EMLA. Sayangnya, pada studi ini tidak ada kelompok placebo sehingga tidak dapat diketahui apakah penggunaan baik VAD ataupun EMLA dapat menghasilkan perbedaan perubahan frekuensi nadi yang bermakna pada pasien yang dilakukan pemasangan PIVC dibandingkan tanpa VAD atau EMLA.

Pada studi ini, tidak menunjukkan adanya perbedaan selisih frekuensi nadi yang signifikan antara kelompok VAD dan EMLA $(p=0,557)$. Peningkatan frekuensi nadi yang lebih tinggi terjadi pada kelompok VAD 2 (-3 - 19) dibandingkan kelompok EMLA 2 (-3-16), namun hal ini juga tidak signifikan secara klinis.

Peningkatan frekuensi nadi sendiri menandakan adanya kecemasan. Namun, studi sebelumnya oleh Ahmetovic-Djug dkk. yang mempelajari efek kecemasan terhadap perubahan parameter hemodinamik pada pasien yang menjalani operasi dengan anestesi juga menunjukkan bahwa tidak terdapat perbedaan yang bermakna pada perubahan frekuensi nadi antara kelompok pasien dengan kecemasan rendah, sedang, dan tinggi. Perubahan nilai mean arterial pressure (MAP) antara ketiga kelompok tersebut pun tidak berbeda bermakna. Sebaliknya studi ini menunjukkan bahwa tingkat kecemasan lebih berhubungan dengan dosis obat anestesi yang digunakan, dimana pasien dengan kecemasan yang lebih tinggi membutuhkan dosis obat anestesi yang lebih tinggi. Selain itu, studi ini juga menunjukkan bahwa tingkat kecemasan dipengaruhi oleh pengalaman operasi sebelumnya, dimana pasien dengan pengalaman operasi sebelumnya memiliki tingkat kecemasan yang lebih rendah. ${ }^{6}$ Terkait dengan studi ini, hasil yang lebih signifikan dapat diperoleh jika dilakukan analisis subgrup antara kelompok subjek yang pernah mengalami pemasangan PIVC sebelumnya dan yang tidak.

Tidak didapatkannya hasil yang signifikan pada studi ini juga dapat diakibatkan oleh rendahnya kemampuan perubahan frekuensi nadi dalam merepresentasikan tingkat kecemasan pasien, 
seperti yang didapatkan pada studi oleh Ahmetovic-Djug, dkk. ${ }^{6}$ Berbeda dengan studi ini, studi oleh McNaughton, dkk. yang mempelajari perbandingan skor kecemasan pada pasien yang menjalani pemasangan kanula intravena perifer dengan lidokain infeksi, krim, dan tanpa anestesi menunjukkan adanya perbedaan skor kecemasan yang signifikan pada kelompok pasien yang diberikan lidokain, baik dalam bentuk injeksi ataupun krim, dibandingkan dengan kelompok yang tidak diberikan anestesi. Skala pengukuran kecemasan yang digunakan pada studi ini yaitu skala angka 1-10. ${ }^{24}$

Berdasarkan hasil dari kedua studi tersebut, studi lebih lanjut untuk membandingkan kemampuan VAD dan EMLA dalam menurunkan tingkat kecemasan pasien yang menjalani pemasangan PIVC dapat menggunakan parameter lain untuk mengukur tingkat kecemasan, seperti skala numerik 0-10 atau skala VAS kecemasan.

\section{Keterbatasan Penelitian}

Keterbatasan penelitian ini yaitu pada metode pengambilan data, dimana tidak dilakukan blinding baik pada pasien maupun observer. Namun, blinding memang tidak mungkin dilakukan karena perbedaan metode perlakuan. Selain itu, adanya perbedaan keterampilan antar operator dalam melakukan pemasangan PIVC juga mungkin dapat menimbulkan bias dalam pengukuran data walaupun kami telah menentukan tingkatan pendidikan yang sama untuk operator.

Studi ini juga belum mengukur respons pasien (kenyamanan/ kepuasan) terhadap aplikasi krim EMLA atau penggunaan alat VAD sendiri, terlepas dari respons nyeri yang dirasakan pasien terkait pemasangan PIVC itu sendiri. Selain mengetahui perbandingan efektivitas EMLA dan VAD dalam mengurangi rasa nyeri terkait pemasangan PIVC, penilaian respons pasien terhadap aplikasi krim EMLA atau penggunaan alat VAD itu sendiri dapat memungkinkan pemilihan metode yang juga lebih nyaman bagi pasien

\section{KESIMPULAN}

Dari penelitian ini didapatkan kesimpulan bahwa VAD sama efektif dibandingkan dengan EMLA dalam mengurangi nyeri pada pemasangan PIVC. Penelitian lebih lanjut yang membandingkan efektivitas dalam mengurangi nyeri menggunakan VAD dan EMLA pada pemasangan PIVC dapat digunakan skala nyeri NRS dan VRS dan dimasukkan penilaian mengenai rasa nyaman, kepuasan dan kecemasan pasien. Penelitian lebih lanjut juga dapat dilakukan untuk menilai efektivitas dalam mengurangi nyeri menggunakan VAD dan EMLA pada pemasangan PIVC untuk pasien anak. Dapat pula dilakukan penelitian dengan alat yang lain / metode lain yang bekerja berdasarkan prinsip gate control theory of pain untuk mengurangi nyeri pemasangan PIVC.

\section{KONFLIK KEPENTINGAN}

Penulis menyatakantidak ada konflik kepentingan dalam penulisan artikel ini.

\section{DAFTAR PUSTAKA}

1. AhmetovicDjug J, Hasukic $S$, Djug $H$, Hasukic B, Jahic A. Impact of Preoperative Anxiety in Patients on Hemodynamic Changes and a Dose of Anesthetic During Induction of Anesthesia. Medical Archives. 2017;71(5):330.

2. Ali, N., Lewis, M. Understanding pain: an introduction for patients and caregivers. Lanham: Rowman \& Littlefield. 2015.

3. BJERRING P, ANDERSEN P, ARENDT-NIELSEN L. VASCULAR RESPONSE OF HUMAN SKIN AFTER ANALGESIA WITHEMLACREAM.British Journal of Anaesthesia. 1989;63(6):655-660.

4. Çelik G, Özbek O, Yılmaz M, Duman I, Özbek S, Apiliogullari S. Vapocoolant Spray vs Lidocaine/Prilocaine Cream for Reducing the Pain of Venipuncture in Hemodialysis Patients: A Randomized, Placebo-Controlled, Crossover Study. International Journal of Medical Sciences. 2011;8(7):623-627.

5. Cooke M, Ullman A, Ray-Barruel G, Wallis M, Corley A, Rickard C. Not "just" an intravenous line: Consumer perspectives on peripheral intravenous cannulation (PIVC). An international cross-sectional survey of 25 countries. PLOS ONE. 2018;13(2):e0193436.

6. Bjerring $H$. Effect of EMLA Cream on Skin Thickness and Subcutaneous Venous 
Diameter. A Randomized, Placebocontrolled Study in Children. Acta DermatoVenereologica. 2000;80(5):340-343.

7. Ehrenström-Reiz G, Reiz S, Stockman O. Topical Anaesthesia with EMLA, a New Lidocaine-Prilocaine Cream and the Cusum Technique for Detection of Minimal Application Time. Acta Anaesthesiologica Scandinavica. 1983;27(6):510-512.

8. Griffith R, Jordan V, Herd D, Reed P, Dalziel S. Vapocoolants (cold spray) for pain treatment during intravenous cannulation. Cochrane Database of Systematic Reviews. 2016;

9. Kumar S, Sanjeev O, Agarwal A, Shamshery C, Gupta R. Double blind randomized control trial to evaluate the efficacy of ketoprofen patch to attenuate pain during venous cannulation. The Korean Journal of Pain. 2018;31(1):39-42.

10. Lanitis S, Mimigianni C, Raptis D, Sourtse G, Sgourakis G, Karaliotas C. The Impact of Educational Status on the Postoperative Perception of Pain. The Korean Journal of Pain. 2015;28(4):265-274.

11. Lee C, Yeoh C. Pain during venous cannulation: Double-blind, randomized clinical trial of analgesic effect between topical amethocaine and eutectic mixture of local anesthetic. Journal of Anaesthesiology Clinical Pharmacology. 2012;28(2):205.

12. Lundeberg T, Nordemar R, Ottoson D. Pain alleviation by vibratory stimulation. Pain. 1984;20(1):25-44.

13. Mally P, Czyz C, Chan N, Wulc A. Vibration Anesthesia for the Reduction of Pain with Facial Dermal Filler Injections. Aesthetic Plastic Surgery. 2014;38(2):413-418.

14. McNaughton C, Zhou C, Robert L, Storrow A, Kennedy R. A Randomized, Crossover Comparison of Injected Buffered Lidocaine, Lidocaine Cream, and No Analgesia for Peripheral Intravenous Cannula Insertion. Annals of Emergency Medicine. 2009;54(2):214-220.

15. Nanitsos E, Vartuli R, Forte A, Dennison $P$, Peck $C$. The effect of vibration on pain during local anaesthesia injections. Australian Dental Journal. 2009;54(2):94-100.

16. Rickard C, Webster J, Wallis M, Marsh N, McGrail M, French $V$ et al. Routine versus clinically indicated replacement of peripheral intravenous catheters: a randomised controlled equivalence trial. The Lancet. 2012;380(9847):1066-1074

17. Rodriguez-Calero, M., Fernandez-Fernandez, I., Molero-Ballester, L., Matamalas-Massanet, C., Moreno-Mejias, L., de Pedro-Gomez, J., Blanco-Mavillard, I. and Morales-Asencio, J., 2018. Risk factors for difficult peripheral venous cannulation in hospitalised patients. Protocol for a multicentre case-control study in 48 units of eight public hospitals in Spain. BMJ Open, 8(2), p.e020420.

18. Speirs, A., Taylor, K., Joanes, D. and Girdler, N., 2001. A randomised, double-blind, placebocontrolled, comparative study of topical skin analgesics and the anxiety and discomfort associated with venous cannulation. British Dental Journal, 190(8), pp.444-449.

19. Haydar, B., 2015. Stoelting's Pharmacology and Physiology in Anesthetic Practice, 5th Edition: Stoelting's Handbook of Pharmacology and Physiology in Anesthetic Practice, 3rd Edition. Anesthesiology, 122(6), pp.1445-1445.

20. Uman, L., Birnie, K., Noel, M., Parker, J., Chambers, C., McGrath, P. and Kisely, S., 2013. Psychological interventions for needle-related procedural pain and distress in children and adolescents. Cochrane Database of Systematic Reviews, .

21. Wandner, L., Scipio, C., Hirsh, A., Torres, C. and Robinson, M., 2012. The Perception of Pain in Others: How Gender, Race, and Age Influence Pain Expectations. The Journal of Pain, 13(3), pp.220-227.

22. Woelfel, I. and Takabe, K., 2016. Successful intravenous catheterization by medical students. Journal of Surgical Research, 204(2), pp.351-360.

23. Zempsky, W., 2008. Pharmacologic Approaches for Reducing Venous Access Pain in Children. Pediatrics, 122(Supplement 3), pp.S140-S153.

24. McNaughton, C., Zhou, C., Robert, L., Storrow, A. and Kennedy, R., 2009. A Randomized, Crossover Comparison of Injected Buffered Lidocaine, Lidocaine Cream, and No Analgesia for Peripheral Intravenous Cannula Insertion. Annals of Emergency Medicine, 54(2), pp.214-220. 